\title{
Filiações epistemológicas em projetos de mestrado em Psicologia: Estudo sobre os autores que os fundamentam
}

\author{
Epistemological links in psychology master projects: \\ A study about the authors that underlie them
}

\author{
Jesus Garcia Pascual[a], Áurea Júlia de Abreu Costa ${ }^{[b]}$, Janailson Monteiro Clarindo ${ }^{[c]}$
}

\footnotetext{
${ }^{[a]}$ Doutor em Educação pela Universidade Federal do Ceará (UFC), professor do Departamento de Psicologia da Universidade Federal do Ceará (UFC), professor do Mestrado em Psicologia da mesma Universidade, Fortaleza, CE - Brasil, e-mail: garciapascual2001@yahoo.com.br

${ }^{[b]}$ Mestre em Psicologia pela Universidade Federal do Ceará (UFC), bolsista da Coordenação de Aperfeiçoamento de Pessoal de Nível Superior (Capes/Reuni), Fortaleza, CE - Brasil, e-mail: aureajulia@yahoo.com.br

${ }^{[c]}$ Mestrando do Programa de Pós-Graduação em Psicologia na Universidade Federal do Ceará (UFC), membro do Programa de Educação Tutorial PET/Psicologia, Universidade Federal do Ceará (UFC), Fortaleza, CE - Brasil, e-mail: janailson_21@yahoo.com.br
}

Recebido: 13/04/2011 Received: 04/13/2011

Aprovado: 04/11/2011 Approved: 11/04/2011

\section{Resumo}

O aumento da procura por cursos de pós-graduação no Ceará suscita o interesse pela investigação de aspectos concernentes aos mesmos. 0 presente artigo investiga as referências bibliográficas utilizadas, em projetos de mestrado, pelos candidatos que se submeteram à seleção do mestrado em Psicologia em universidade situada na cidade de Fortaleza (CE), no período de 2006 a 2010. Trata-se de pesquisa bibliográfica/documental, cujo acervo consta de livros e documentos: fontes de estudo sobre a Psicologia - livros-texto, livros sobre epistemologia da Psicologia, livros-roteiro - e 52 projetos de mestrado. Recorremos aos livros para definir o que designamos por "autores basilares" na configuração da ciência psicológica - fundadores de teorias psicológicas ou fomentadores reconhecidos das mesmas. Os 52 projetos de mestrado foram analisados quanto às referências bibliográficas utilizadas como fundamentação teórica, as quais foram comparadas com aquelas citadas nos livros-texto, livros sobre epistemologia da Psicologia e livros-roteiro. Isso nos permitiu identificar a proporcionalidade entre a utilização de "autores basilares" e a utilização de "autores emergentes", aqueles que começam a ser referenciados em trabalhos científicos, mas não têm, ainda, contribuições consolidadas para o desenvolvimento da Psicologia. Os resultados da pesquisa mostram que os candidatos à Pós-Graduação em Psicologia mantêm equilíbrio na fundamentação teórica dos projetos, pois recorrem preferencialmente a "autores basilares" da Psicologia e de outras ciências, bem como, promovem o aparecimento de novos nomes no cenário científico psicológico, os "autores emergentes".

Palavras-chave: Epistemologia. Psicologia. Autoria. Coautoria. Publicação científica.

\section{Abstract}

The increase in demand for post-graduate courses in Ceará (Brazil) raises interest in research of aspects concerning them. This article investigates the bibliographical references used in master projects, by candidates who were submitted to the selection of a master degree in Psychology in a university located in Fortaleza, Ceará, in the period from 2006 to 2010. This is a bibliographic/documental research, whose collection consists of books and documents: sources of study about Psychology - textbooks, psychology epistemology books, guide books - and fifty-two master projects. The books were used to define "basic authors" in the configuration of 
Psychological Science (psychological theories founders or recognized promoters of them). The references of the fifty-two master projects were analyzed and compared with those cited in the textbooks, psychology epistemology books and guide books. This allowed us identify the proportion between the use of "basic authors" and the use of authors, characterized as "emerging authors", those who begin to be referenced in scientific papers, but have not yet consolidated contributions to the development of psychology. The survey results show that candidates for the Psychology Graduate Program keep balance in the theoretical foundations of the projects. They use preferentially the "basic authors" of psychology and of the other sciences, but they also promote the emergence of new names in the scientific psychological, the "emerging authors".

Keywords: Epistemology. Psychology. Authorship. Co-authorship. Scientific publications.

\section{Introdução}

Torna-se evidente a disseminação de cursos de Psicologia no âmbito nacional durante as décadas 1990 e 2000. Cabe notar que nas regiões Norte, Nordeste e Centro-Oeste existem, atualmente, cerca de 96 cursos de Psicologia. Referimo-nos em particular a essas três regiões porque um dos autores do trabalho participa do RIDES - Rede InterRegional de Educação Superior (Norte, Nordeste e Centro-Oeste).

A expansão de cursos de graduação gera, por sua vez, desdobramentos do saber psicológico na pós-graduação. Não só os alunos de Psicologia procuram os cursos de pós-graduação, mas concludentes de outras áreas - tais como Letras, História, Arquitetura, Serviço Social, Enfermagem etc. também concorrem nas seleções para o mestrado. Talvez porque, para alguns concludentes, educação seja considerada necessidade e, daí, a procura. Se assim for, a pós-graduação "qualifica pesquisadores, profissionais e professores do ensino superior em Psicologia, e áreas afins, para o enfrentamento de questões contemporâneas, no âmbito da produção da subjetividade, do sofrimento humano e da atenção às demandas sociais" (Universidade Federal do Ceará, [UFC], 2005).

Se tal é a responsabilidade dos cursos de pós-graduação, como avaliar a qualidade da formação científica e profissional para além da graduação e em consonância com as demandas sociais, sendo que a profissão dos psicólogos passou por várias fases no Brasil? A formação de psicólogos brasileiros apresenta tendências diferenciadas no exercício da profissão (Araújo \& Almeida, 2005). De 1930 até a década de 1960 , predominaram as tendências psicométrica e experimental que formavam psicólogos técnicos na aplicação de testes. E, nesse sentido, cabe ressaltar que avaliação e psicologia caminhavam parelhas nessa época, como constata Sobrinho (2003, p. 16): "Avaliação confunde-se com medição e se insere basicamente no campo da psicologia. Daí ter se tornado amplamente disseminado o conceito de psicometria".

Ao referendar-se como profissão, mediante a Lei n. 4.119, de 27 de agosto de 1962, a Psicologia assumiu a perspectiva liberal e positivista, instruindo as práticas profissionais como verdadeiros vigias do desenvolvimento "normal". A década de 1970 foi marcada por reflexões epistemológicas e conceituais na tentativa de definir referenciais teóricos que sustentassem a atividade profissional (Pessotti, 1988).

A década de 1980 caracterizou-se pelas lutas sociais em busca de melhores condições de vida no trabalho, na saúde, na educação, na política, e, desse modo, os psicólogos, ao juntar-se às lutas sociais, começaram a veicular uma visão histórica e crítica de homem e de fenômeno psicológico (Lane \& Codo, 1989). Conforme comentam Araújo e Almeida (2005), os anos 90 "distinguiram-se pela diversidade do trabalho dos psicólogos, ao lado da cada vez mais crescente tendência pelo questionamento e reformulação de teorias, métodos, atuações e intervenções psicológicas" (Lane \& Codo, 1989, p. 15).

E nos alvores do terceiro milênio? Atrevemonos a sinalizar o nascimento de novo paradigma na Psicologia, gestado em diálogos transdisciplinares (Antropologia Cultural, Sociologia, Linguística, Neurociência, Ecologia, História - dentre outros campos do conhecimento) e transmetodológicos (métodos etnográficos, métodos cartográficos, métodos discursivos) como alternativas científicas 
válidas ao Positivismo e ao Estruturalismo e alternativas metodológicas válidas ao caminho hegemônico do método científico positivo, respectivamente. Se tal prenúncio for correto, parece evidente o surgimento de autores novos no cenário da Psicologia que alimentem as teorias e as práticas psicológicas.

É nesse contexto epistemológico que surgem as perguntas geradoras da pesquisa que enseja este texto. Perguntamo-nos:

a) 0 surgimento maciço de autores novos em projetos de seleção para o mestrado em Psicologia supõe o descarte de "autores basilares" na configuração dessa ciência, isto é, fundadores de teorias psicológicas ou fomentadores reconhecidos das mesmas?

b) A recorrência a "autores basilares" na configuração de outros campos científicos - antropológico, cultural, lingüístico, filosófico etc. - predomina em projetos de seleção para o mestrado em Psicologia com relação a "autores basilares" do saber psicológico propriamente dito?

c) Levando-se em conta o número total de referências autorais constantes dos projetos de mestrado, predominam "autores basilares" da Psicologia, "autores basilares" de outras ciências ou "autores emergentes", isto é, autores que começam a ser referenciados em trabalhos científicos, haja vista sua relevância para discutir problemas teóricos da Psicologia ou transformar realidades psicossociais concretas?

Os resultados da pesquisa mostram que os candidatos à pós-graduação em Psicologia mantêm equilíbrio na fundamentação teórica dos projetos, pois, recorrendo preferencialmente a "autores basilares" da Psicologia e de outras ciências, também promovem o aparecimento de novos nomes no cenário científico psicológico, "autores emergentes". Constata-se, todavia, o afluxo de nomes autorais que mereceriam melhor reconhecimento científico. Isso não deve ser entendido como interdito científico-acadêmico, mas como reflexo do açodamento entre certos intelectuais que muitas vezes privilegiam a novidade autoral em si em detrimento da segurança confirmada. $\mathrm{O}$ vinho novo despejado açodadamente em odres velhos, azeda, mas, vinho velho despejado em odres novos, dilacera-os. Cabe-nos na contemporaneidade, portanto, acertar leituras velhas e novas. Eis o desafio que abordamos nas próximas páginas.

\section{A pesquisa que provoca este trabalho}

\section{Relevância do tema}

Se a procura por cursos de pós-graduação vem aumentando no Ceará, torna-se conveniente investigarmos aspectos relativos aos mesmos. 0 assunto que focamos na pesquisa foi a bibliografia citada por candidatos que apresentam projetos para ingressar num programa de mestrado em Fortaleza. Tal interesse surgiu como terceira via de reflexão crítica em relação ao uso de fontes bibliográficas entre outras já existentes. De um lado, encontramos textos que buscam apoio teórico em livros antigos - verdadeiros sarcófagos contendo ossos incinerados que não refletem as características sociais, culturais e científicas da atualidade em Psicologia - mas, por outro lado, os programas de fomento da ciência (Capes, CNPq, etc.) encurtam a cada dia o tempo das publicações que sustentam textos científicos - sob a alegação de atualização obsessiva (atualismo?) das referências. Por isso, investigamos, nesta terceira via, as referências bibliográficas em projetos de mestrado, analisando a proporcionalidade entre autores que tenham contribuições relevantes na Psicologia, independentemente da data de publicação - autores basilares -, e autores recentes, mas levando em conta as contribuições para essa área de conhecimento - autores emergentes. Eis como nasceu o objetivo da pesquisa que dá ensejo ao texto ora apresentado.

A pesquisa, na sua abrangência, foca a Graduação e a Pós-Graduação em Psicologia no Ceará, cujo período de realização vai de 2010 a 2012. Recortamos, neste trabalho, os resultados já consolidados no que tange ao uso de autores citados e representativos na Psicologia, "autores basilares", utilizados na confecção dos projetos de seleção ao mestrado comparando sua frequência com outros autores citados, "autores emergentes" que não tenham ainda contribuições consolidadas para o desenvolvimento da Psicologia. Tal assunto torna-se relevante, uma vez que constatamos na pesquisa a presença de autores cujas contribuições ao saber psicológico não são tão 
relevantes - por tratar-se de relevância teórica regional brasileira - em detrimento de expoentes no campo da Psicologia cuja relevância teórica para a Psicologia alcança dimensões nacionais e internacionais. Como elencar, entretanto os representantes relevantes sem cairmos na escolha subjetiva, o que invalidaria a pesquisa?

\section{Campo da pesquisa}

O Mestrado que ora nos ocupa situa-se no estado do Ceará e investiga, segundo o projeto pedagógico (www.pospsi.ufc.br), assuntos de Psicologia em três linhas de pesquisa, a saber:

a) Psicanálise, práticas clínicas e epistemologia das psicologias, cuja descrição no site aparece da seguinte forma:

Objetiva a realização de investigações teóricas e clínicas acerca da constituição do sujeito, seus modos de organização psíquica e suas relações com os processos sintomáticos responsáveis pela configuração dos diversos quadros psicopatológicos. Tal concerne ao campo da Psicanálise e de outras práticas clínicas. Tem, ainda, como objetivo promover estudos e pesquisas relacionados com os fundamentos epistemológicos das psicologias: a metapsicologia freudiana e a abordagem psicogenética (UFC, 2005).

b) Cultura e subjetividades contemporâneas, cuja descrição no site aparece da seguinte forma:

A partir de uma preocupação comum com a inserção da Psicologia no debate crítico e ético acerca da cultura contemporânea, em suas interfaces com campos afins, esta linha tem como objetivo refletir sobre diversos aspectos que afetam as subjetividades contemporâneas, a saber: a cultura do consumo, a mídia e as novas tecnologias e outros fatores significativos da condição tardomoderna, incluindo o papel da literatura na constituição do sujeito. A linha inclui também estudos sobre a produção de sentido e as práticas discursivas de indivíduos e coletividades na perspectiva de uma Psicologia Discursiva/Narrativa (UFC, 2005). c) Processos de mediação: trabalho, atividade e interação social, cuja descrição no site aparece da seguinte forma:

Esta linha congrega estudos e pesquisas que optam por uma perspectiva social da psicologia, enfocando por um lado o referencial teórico-metodológico que segue os pressupostos da Teoria Histórico-Cultural e suas derivações, e por outro a reflexão do trabalho como categoria social e território de construção subjetiva do sujeito contemporâneo. Tal orientação tem norteado os trabalhos desenvolvidos pelos professores desta linha, os quais atuam em áreas diversas, tais como: Psicologia Social, Psicologia Comunitária, Psicologia Social do Trabalho, Psicologia Ambiental e Psicologia do Desenvolvimento (UFC, 2005).

Diante das linhas de pesquisa propostas pelo Mestrado, torna-se evidente que autores referenciados nos projetos deverão ser pesquisadores reconhecidos na psicanálise, na teoria crítica, no pós-estruturalismo e na teoria sócio-histórica. Cabe fazer aqui uma observação quanto à primeira linha de pesquisa, que atualmente recebe projetos de candidatos quase exclusivamente na psicanálise. Por isso, só referiremos livros concernentes a essa área do conhecimento. 0 critério para selecionar autores representativos em cada linha de pesquisa do Mestrado foi que seu nome aparecesse, pelo menos, em duas das três fontes bibliográficas/documental - livros-texto, livros sobre epistemologia da Psicologia, livros-roteiro.

\section{Fontes da pesquisa}

Para superar esse desafio, recorremos a fontes bibliográficas reconhecidas pelo uso pedagógico e pela divulgação, em âmbito nacional e internacional (pesquisa bibliográfica), às referências bibliográficas de disciplinas do Mestrado e aos projetos de mestrado (pesquisa documental). Embora apresentem características semelhantes, os dois modelos não são iguais; Gil (1995, p. 71) esclarece esse aspecto:

A pesquisa bibliográfica é desenvolvida a partir de material já elaborado, constituído principalmente de livros e artigos científicos. Embora em quase 
todos os estudos seja exigido algum tipo de trabalho desta natureza, há pesquisas desenvolvidas exclusivamente a partir de fontes bibliográficas.

No que se refere à pesquisa documental, o autor sinaliza os pontos de semelhança e de divergência entre elas:

A pesquisa documental assemelha-se muito à pesquisa bibliográfica. A única diferença entre ambas está na natureza das fontes. Enquanto a pesquisa bibliográfica se utiliza fundamentalmente das contribuições dos diversos autores sobre determinado assunto, a pesquisa documental vale-se de materiais que não receberam ainda um tratamento analítico, ou que ainda podem ser reelaborados de acordo com os objetivos da pesquisa (Gil, 1995, p. 73).

Seguindo a descrição que o autor faz e focando o objeto de investigação em livros, mas também em referências bibliográficas apontadas por uma disciplina do curso pesquisado, trata-se fundamentalmente de pesquisa bibliográfica/documental, cujo acervo foi dividido nos documentos referidos a seguir. As fontes de estudo sobre a Psicologia são:

a) livros-texto - Glasman e Hadad (2008), Gleitman, Reisberg e Gross (2009), Griggs (2009), Bock, Furtado e Teixeira (2009), Coll, Marchesi e Palácios (2004);

b) livros sobre epistemologia da Psicologia Penna (1991), Carpintero (2003), Figueiredo (2007), Disciplinas do Mestrado;

c) livros-roteiro - Sheehy (2006); Lechte (2003);

d) cinquenta e dois projetos de mestrado, apresentados nas seleções entre os anos de 2006 e 2010 .

A escolha do primeiro grupo - livros-texto decorre da importância desses manuais já que o livro didático talvez seja uma das modalidades mais antigas de expressão escrita, já que é uma das condições para o funcionamento da escola (Lajolo \& Zilberman, 1996). Sua relevância nesta pesquisa fica comprovada porque são livros atuais, reconhecidos e referenciados no Brasil e no exterior para uso em cursos de graduação, podendo ser estendidos à pós-graduação. Seus autores compõem os quadros de professores doutores em universidades de excelente envergadura científica nos respectivos países:

- Ana Maria Bahia Bock, Odair Furtado e Maria de Lourdes Trassi Teixeira lecionam na Universidade de São Paulo (USP) e seu livro-texto passa pela $14^{\mathrm{a}}$ ediç̧̃ã

- os professores William Glassman, Emérito da Ryerson University (Toronto) e Marylin Hadad, da mesma universidade, elaboraram o livro-texto que atinge no Brasil sua quarta edição;

- Richard A. Griggs leciona na Universidade da Flórida (USA) e seu livro está na segunda edição entre nós;

- o livro-texto, elaborado pelos professores Henry Gleitman, Emérito na Universidade da Pennsylvania, Daniel Reisberg, professor da Universidade de Portland (Oregon), e James Gross, professor de Stanford, elaboraram o livro-texto que atinge no Brasil sua sétima edição.

- o livro-texto elaborado pelos professores César Coll, Universidade de Barcelona, Álvaro Marchesi, Universidade Complutense (Madrid), e Jesús Palacios, Universidade de Sevilla, teve sua segunda edição reimpressa no Brasil pela sétima vez.

No que tange à importância do segundo grupo livros sobre epistemologia da Psicologia -, recorremos ao pensamento de epistemólogos consagrados (Lakatos, 1989; Bachelard, 1996), que mostram a importância da forma como conseguimos o conhecimento: "A filosofia das ciências sem a história das ciências é vazia; a história das ciências sem a filosofia das ciências é cega" (Lakatos, 1989, p. 59). Acrescenta Bachelard (1996, p. 96): "Para julgar adequadamente o passado, o historiador das ciências deve conhecer o presente; deve conhecer o melhor possível a ciência cuja história se propõe escrever".

Em decorrência disso, selecionamos apenas três livros porque os estudos epistemológicos sobre a Psicologia não são tão frequentes. 0 professor Antônio Gomes Penna dispensa apresentação nos círculos de intelectuais da Psicologia; professor emérito da UFRJ, ele escreveu no início da década de 1980 sobre a história das ideias psicológicas. Mas o que pretendia ser apenas Uma breve História das idéias psicológicas (Penna, 1991, p. 11) permanece 
ainda como um livro de referência para os estudiosos da história da Psicologia. 0 autor afirma que "não é e não poderia ser um texto de história da psicologia. A história da psicologia é a história de uma ciência... cobre um período reduzido de tempo... fins do século XIX e se estende até o presente" (Penna, 1991, p. 11).

0 tema da epistemologia volta ao campo psicológico na década de 1990, mormente nas obras do professor da Universidade de São Paulo (USP) Luís Cláudio Mendonça Figueiredo. Cabe salientar que seu livro Matrizes do pensamento psicológico, publicado pela primeira vez em 1991 encontra-se na nona edição e, "embora redigido com o objetivo de alcançar prioritariamente alunos de pós-graduação e profissionais da área $p s i$, poderá ser também usado como livro de texto em disciplinas de História da psicologia e ou Teorias e sistemas em cursos de graduação" (Figueiredo, 2007, p. 12). Helio Carpintero, professor titular da Universidad Complutense (Madri) tem publicados mais de quinze (15) livros sobre Psicologia, sendo que o livro História de las Ideas psicológicas atingiu na Espanha a segunda edição em 2005.

Além dos três livros citados, acrescentamos documentos (e nesse sentido, concedemos-lhe menor base científica; de acordo com Gil (1995), "a pesquisa documental vale-se de materiais que não receberam ainda um tratamento analítico") que são disciplinas. Esses documentos fornecem literatura consistente para identificar autores importantes nas linhas de pesquisa traçadas pelo Mestrado, pois seu objetivo principal é promover reflexões epistemológicas acerca das principais teorias atuais na Psicologia.

Compõem o terceiro grupo - livros-roteiro - dois livros que foram publicados para elencar 50 grandes psicólogos e 50 pensadores desde o final do século XIX até as datas de suas publicações, 2006 e 2003, respectivamente. Utilizamo-nos dos livros de John Lechte (2003), professor da Macquarie University (Austrália), e de Noel Sheehy, professor de Ciências Naturais e de Psicologia na Universidade John Moores (Liverpool), apenas como catálogo de autores por ele citado, mas não asseveramos a escolha feita.

Concomitantemente, analisamos no quarto grupo - projetos de mestrado - 52 projetos de candidatos ao Mestrado, sem levar em conta se foram aprovados ou não. Não consideramos, para efeitos da pesquisa, a linha escolhida pelo candidato, mas os livros que ele referencia no projeto como fontes teóricas no que concerne à fundamentação do problema encetado. Conseguimos anotar, na fonte bibliográfica/documental, composta pelos grupos 1, 2 e 3 (texto, epistemologia, roteiro, respectivamente), 198 referências. No que tange à fonte só documental (projetos de mestrado), coligimos 680 referências de autores.

Os resultados tabulados mostram de forma conjunta, as semelhanças e diferenças entre as duas fontes da pesquisa, a saber, bibliográfica/documental e só documental (Tabela 1). Comparamos apenas os autores que foram citados três ou mais vezes somando as duas fontes da pesquisa e as elencamos em ordem decrescente, perfazendo o total de 19 autores que são indicados pelos livros/disciplinas (primeira fonte, bibliográfica/documental) e que aparecem nos projetos (segunda fonte, só documental). Cabe assinalar que a lista de autores citados uma ou duas vezes é muito grande e não cabe trazê-la neste texto. Sendo assim, a análise dos resultados restringir-se-á aos autores mais representativos na investigação.

\section{Resultados da pesquisa}

Em relação às fontes consultadas, contamos 878 citações/chamadas. E sendo assim, analisamos os resultados tendo como parâmetro as três linhas de pesquisa do Mestrado. Sigmund Freud (1856-1939) é o autor mais citado e o consideramos como "autor basilar" da linha de pesquisa Psicanálise, práticas clínicas e epistemologia das psicologias. Constatamos seu nome em 42 ocasiões, o que equivale a $4,8 \%$ em relação ao total das citações. Atente-se, contudo, para essa percentagem porque na primeira fonte (bibliográfica/documental) atinge maior evidência (16\%) do que na segunda fonte (só documental) $1,4 \%$. Constatamos que o fundador da psicanálise não vem acompanhado na mesma proporção por outros autores da área, pois Carl Gustav Jung (18751961) - parceiro e dissidente - é citado 15 vezes, isto é, $1,7 \%$. Observamos que um autor, mesmo não considerado fundador, adquire hoje uma projeção no que concerne à epistemologia da psicanálise. Trata-se de Paul-Laurent Assoun (1948...) que são citados cinco vezes $(0,5 \%)$ e autores mais próximos 
Tabela 1 - Autores mais representativos na investigação

\begin{tabular}{|c|c|c|c|c|}
\hline \multicolumn{2}{|c|}{ Autores citados } & \multirow{2}{*}{$\begin{array}{c}\text { Bibliográfica/documental } \\
32\end{array}$} & \multirow{2}{*}{$\begin{array}{c}\text { Só documental } \\
10\end{array}$} & \multirow{2}{*}{$\begin{array}{c}\text { Total } \\
42\end{array}$} \\
\hline $1^{\mathrm{o}}$ & S. Freud & & & \\
\hline $2^{o}$ & M. Foucault & 18 & 11 & 29 \\
\hline $3^{\circ}$ & L. Vygotsky & 12 & 07 & 19 \\
\hline $44^{\circ}$ & C. Jung & 09 & 06 & 15 \\
\hline \multirow[t]{3}{*}{$5^{\circ}$} & A. Luria & 10 & 02 & 12 \\
\hline & C. L. Góis & 03 & 09 & 12 \\
\hline & R. L. Costa Antunes & 00 & 12 & 12 \\
\hline $6^{0}$ & J. Bruner & 09 & 01 & 10 \\
\hline \multirow[t]{2}{*}{$7^{0} \stackrel{0}{ }$} & R. Herrstein e E. Boring & 09 & 00 & 09 \\
\hline & J. Derridá & 07 & 01 & 09 \\
\hline \multirow[t]{3}{*}{$8^{0}$} & T. Adorno e M. Horkheimer & 04 & 03 & 07 \\
\hline & P. Freire & 03 & 06 & 07 \\
\hline & F. Gonzalez Rey & 03 & 04 & 07 \\
\hline 9o & G. Bachellar & 03 & 03 & 06 \\
\hline \multirow[t]{3}{*}{$10^{\circ}$} & J. V. Wertch & 05 & 00 & 05 \\
\hline & P. Assoun & 05 & 00 & 05 \\
\hline & L.C. Figueiredo & 02 & 03 & 05 \\
\hline $11^{\circ}$ & S. Lane & 00 & 04 & 04 \\
\hline $12^{\circ}$ & E. Morin & 00 & 03 & 03 \\
\hline
\end{tabular}

Fonte: Dados da pesquisa.

dos fundadores, Melanie Klein, por exemplo, são citados apenas duas vezes.

Em segundo lugar aparece o nome de Michel Foucault (1926-1984), que aparece 29 vezes, o que perfaz 3,3\% do total de citações. Michel Foucault torna-se representante da segunda linha de pesquisa que trata de Cultura e subjetividades contemporâneas. Há dois autores, cujas contribuições para os estudos da cultura e da subjetividade têm contribuído sobremaneira, que aparecem bem referenciados. Um deles, J. Bruner (dez ocorrências), vem contribuindo com estudos sobre a subjetividade há quase um século; o outro, J. Derridá (nove ocorrências), aloca-se nesta linha de pesquisa por causa de seus estudos sobre desconstrução da linguagem. Outro autor relacionado com o pós-estruturalismo e, portanto, pertencente a essa linha de pesquisa, Gilles Deleuze (1925-1995), é citado apenas duas vezes. Temas relacionados à cultura e à subjetividade recebem colaboração teórica dos autores da escola de Frankfurt, como Adorno e Horkheimer, citados sete vezes.

No que tange à terceira linha de pesquisa Processos de mediação: trabalho, atividade e interação social -, o autor bielo-russo, Lev Vygotsky (1896-1934), foi nomeado em 19 ocasiões, atingindo 2,1\% das citações; quanto aos parceiros na troika, Alexander Luria (1902-1977) foi citado 12 vezes, mas Alexei Leontiev (1903-1979) foi lembrado apenas duas vezes. Chama-nos a atenção, ainda nesta mesma linha de pesquisa, a recorrência aos livros escritos por Cézar Wagner de Lima Góis e Costa Antunes (ambos com 12 ocorrências cada), que, embora sejam considerados por nós "autores emergentes", sua recorrência atinge 1,3\% das citações; superando inclusive autores que trabalham com a teoria sócio-histórica há mais tempo, como V. Wertch (5), P. Freire (7), F. Gonzalez Rey (7) ou S. Lane (4).

Há citações, contudo, que fundamentam as três linhas de pesquisa do Mestrado estudado, pois esses 
autores apresentam contribuições reconhecidas no campo da epistemologia, a saber: G. Bachelard (6), L. C. Figueiredo (5) e E. Morin (3). Mas, o manual escrito por Richard Herrstein (1930-1994) e Edwin Boring (1886-1968) que fundamentou a formação de psicólogos na década de 1970 foi citado nove vezes só na fonte de pesquisa bibliográfica/documental e não foi encontrada citação alguma nos projetos.

\section{Considerações finais}

Ao tecermos considerações (in)conclusas, lembramos as recomendações que Juremir Machado da Silva sugere ao pesquisador: "Ao final de um trabalho de pesquisa ..., o pesquisador deve ser capaz de responder a algumas questões muito simples e claras. 0 que foi desvendado? 0 que foi desvelado? 0 que passou de encoberto a descoberto? 0 que emergiu? 0 que veio à tona?" (Silva, 2010, p. 29).

0 que foi desvendado refere-se ao desvendamento, trata-se de retirar a venda que o autor da pesquisa possua em relação ao tema e que possa obnubilar o objeto de estudo. Nosso desvendamento, na condição de autores deste texto, significa reconhecer que existe um acervo bibliográfico muito mais amplo do que aquele com o qual trabalhamos. Daí que a avaliação de trabalhos científicos - no caso, projetos de mestrado - não pode estar pautada apenas em "autores basilares", de reconhecidas safras científico-metodológicas, porque esta pesquisa nos mostra que a recorrência a "autores emergentes" pode renovar a aplicabilidade de teorias consistentes, porém, descontextualizadas regionalmente.

0 que foi desvelado refere-se à revelação do objeto de estudo, isto é, levantar o pano que pode encobrir o assunto pesquisado. Nosso desvelamento do objeto pesquisado, na condição de autores deste texto, representa constatar que os candidatos ao Mestrado conseguem entremear "autores basilares" e "autores emergentes", tecendo uma trama teórica ambígua. A concepção de ambiguidade trazida por E. Morin (2001) nos reporta ao conceito de incerteza, que medeia o antigo e o novo, a ordem e a desordem mostrando-nos que: "O conhecimento humano é dinâmico, provisório e sempre em reestruturação na medida da evolução da visão humana, pois a mente humana ao organizar-se sofre o fenômeno da clausura e abertura, avançando com o tetragrama ordem/desordem/articulação/organização" (Santos, Souza \& Chiquieri, 2010, p. 11).

Entre o desvendamento (aspecto subjetivo na pesquisa) e o desvelamento (aspecto objetivo na pesquisa), o que passou de encoberto a descoberto foi a (im)possibilidade de cindir o ato do conhecimento entre sujeito e objeto. Sujeito, na condição de portador de conceitos, valores e atitudes forjadas ao longo de seu caminho profissional; e objeto, talhado de acordo com determinado paradigma científico. Portanto, avaliar projetos de mestrado, onde se encontram sujeito (professor) e objeto (projeto) requer reflexões para além da constatação de "autores basilares" como critério do conhecimento da linha de pesquisa para a qual o projeto se destina. Porque avaliar, nos diz Sobrinho (2003, p. 10), produz efeitos públicos, e, sendo assim: "É importante, então, discutir as bases epistemológicas da avaliação, que emergem sempre de concepções de mundo, e vinculá-las com os efeitos pedagógicos, éticos e políticos que produz". Quando candidatos ao mestrado formatam projetos, ancorados em "autores emergentes", desafiam os princípios de velhos professores que, por vezes, ancilosam o avanço da Psicologia. Mas, quando os candidatos tentam revolucionar o campo da Psicologia com emergências autorais meramente midiáticas, mas sem comprovação científica, cabe aos novos professores alimentar-se das teorias psicológicas amplamente consolidadas.

0 que veio à tona, para finalizar este trabalho, foi a gama (in)finita de autores que trabalham (a)nonimamente no campo psicológico e periférico, que convém avaliá-los ponderadamente para não desistir de novas inteligências penetrantes no campo da Psicologia, mas ao mesmo tempo, filtrar as autorias que apenas queiram instalar-se promocionalmente na ciência psicológica. Por sua vez, torna-se iniludível ao avaliador de projetos de mestrado levar em conta a convocação de autores consolidados ("autores basilares") no pensar e no que-fazer da Psicologia contemporânea.

Sendo assim, avaliar e selecionar projetos de mestrado não se configura como apenas escolha meritocrática, mas como decisão científica, social e ética no que concerne à contribuição que os projetos possam trazer para a região, para a nação e para a pátria-terra, nas palavras iluminadas de Edgar 
Morin. Epigrafamos os últimos espaços deste trabalho com as palavras impressas na quarta-capa do livro de José Dias Sobrinho (2003):

A avaliação tem hoje centralidade tanto nos processos de reformas das instituições e do sistema demandadas pelo mercado e impulsionadas pelos Estados, quanto para produzir mais qualidade social e científica, pertinência e sentido público ao conjunto de educação superior.

\section{Referências}

Araújo, C., \& Almeida, S. (2005). Psicologia Escolar. Construção e consolidação da identidade profissional. Campinas, SP: Alínea.

Bachelard, G. (1996). O novo espírito científico. Lisboa: Edições 70.

Bardin, L. (2008). Análise de conteúdo. Brasil: Edições 70.

Bock, A., Graça, M., \& Gonçalves, M. (Org.). (2007). Psicologia sócio-histórica. Uma perspectiva crítica em psicologia. (3a ed.). São Paulo: Cortez.

Bock, A., Furtado, O., \& Teixeira, M. (2009). Psicologias. Uma introdução ao estudo de psicologia. São Paulo: Saraiva.

Brasil. (1962). Lei n. 4.119, de 27 de Agosto de 1962. Dispõe sobre os cursos de formação em psicologia e regulamentaa profissãodepsicólogo. Brasília, DF. Recuperado em 10 out. 2010, de http://www6.senado.gov.br/ legislacao/ListaNormas.action?numero=4119\&tipo norma $=$ LEI\&data $=19620827 \&$ link=s.

Carpintero, H. (2003). Historia de las ideas psicológicas. Madrid: Pirâmide.

Coll, C., Marchesi, A., \& Palácios, J. (2004). Desenvolvimento psicológico e educação. Psicologia da educação escolar. (2a ed.). Porto Alegre: Artmed.

Figueiredo, L. C. (2007). Matrizes do pensamento psicológico. (13a ed.). Petrópolis, RJ: Vozes.

Gil, A. C. (1995). Métodos e técnicas de pesquisa social. (4a ed.). São Paulo: Atlas.

Glasman, W., \& Hadad, M. (2008). Psicologia. Abordagens atuais. Porto Alegre: Artmed. PMid:18851276.
Gleitman, H., Reiberg, D., \& Gross. J. (2009). Psicologia. Porto Alegre: Artmed. PMid:20095191.

Gonzalez Rey, F. (2005). Sujeito e subjetividade. Uma aproximação histórico-cultural. São Paulo: Pioneira Thomson Learning. PMCid:1224633.

Griggs, R. (2009). Psicologia. Uma abordagem concisa. Porto Alegre: Artmed.

Lajolo, M., \& Zilberman, R. (1996). A formação da leitura no Brasil. São Paulo: Ática. PMid:8909980.

Lakatos, I. (1989). La metodología de los programas de investigación científica. Madrid: Alianza. PMCid:1385517.

Lane, S., \& Codo, W. (Org.). (1989). Psicologia Social. O homem em movimento. (7a ed.). São Paulo: Brasiliense.

Lechte, J. (2003). 50 Pensadores contemporâneos essenciais. Do Estruturalismo à Pós-Modernidade. (3a ed.). Rio de Janeiro: Difel.

Morin, E. (2001). Os sete saberes necessários à educação do futuro. (3a ed.). São Paulo: Cortez.

Penna, A. (1991). História das idéias psicológicas. (2a ed.). Rio de Janeiro: Imago.

Pessotti, I. (1988). Notas para uma história da psicologia brasileira. In Conselho Federal de Psicologia. Quem é o psicólogo brasileiro? (pp.17-31). São Paulo: Edicon.

Santos, A., Souza, A., \& Chiquieri, A. (2010). Os sete saberes sob a ótica da didática. In Conferência Internacional sobre os sete saberes, Fortaleza: UECE.

Sheehy, N. (2006). 50 grandes psicólogos. Suas ideais, suas influências. São Paulo: Contexto.

Silva, J. M. (2010). O que pesquisar quer dizer: Como pesquisar e escrever textos acadêmicos sem medo da ABNT e da CAPES. Porto Alegre: Sulina.

Sobrinho, J. D. (2003). Avaliação. Políticas educacionais e reformas da educação superior. São Paulo: Cortez. PMCid:143665.

Universidade Federal do Ceará, [UFC], (2005). Programa de Pós-Graduação em Psicologia. Apresentação. Recuperado em 7 set. 2010, de http://www.pospsi. ufc.br/index.php?option=com_content\&view=article \&id $=46 \&$ Itemid $=60$. 